\title{
A Public 3D Visualization Tool for the Musée des Arts et Métiers de Paris
}

\author{
Pedro Alessio and Alexandre Topol \\ CNAM CEDRIC - Centre d'étude et recherche en informatique du Cnam \\ 292 Rue St Martin FR-75141 Paris Cedex 03 \\ \{alessi_p, alexandre.topol\} @ cnam.fr \\ http://cedric.cnam.fr
}

\begin{abstract}
Useful and durable knowledge can be built upon the experience of discovering and the construction of a contextual awareness. In this article we present a tool to browse a catalog of 3D objects taken from the Musée des arts et métiers de Paris. The purpose of this multimedia kiosk is to enhance the visit experience by helping users to built meaningful relations between objects and scientific fields. Users select subjects of interest during the visit by collecting cards placed beside the real objects in the museums galleries. The cards are tagged with reactvision fiducial marks that enable the user to manipulate the $3 \mathrm{D}$ object representation on the screen. We present this tool and we focus more precisely on interaction issues both for individuals and groups in a public context and for a private use at home.
\end{abstract}

Keywords: Cultural heritage and learning, web, multimedia integration and interoperation.

\section{$1 \quad$ Introduction}

The article describes the analysis and solutions proposed to the remote access to the digitized 3D objects from the objects stock from the Musée des Arts et Métiers de Paris (Museum of Arts and Crafts). Because they are unique and fragile their manipulation for educational purposes in live public demonstrations are very limited or impossible. However these objects represent a rich complementary source of knowledge for visitors and teachers and this project propose to allow such a remote access through an educational multimedia tool. Numerous projects [1][2][3] propose multimedia display devices in order to enrich museums galleries and virtual reality, augmented reality and mobile devices bring innovative solutions to promote exhibitions. These solutions provide guidance and motivate visitors to dig further for details in a less passive relation with objects. But works [4][5] reveal some issues on user engagement towards the public interface devices and the digital content proposed. This happens mostly when the task is a challenging experience like manipulating 3D virtual objects causing users to rapidly lose focus and interest. To answer this issue, we propose a multimedia kiosk that links tightly real objects of the museum with a 3D virtual objects database by the use of simple input system based on paper cards col- 
lected during the visit. These cards serve as input devices for viewing and manipulating the 3D representations and also as a physical link to a post-visit moment. The multiuser kiosk is based on a reactvision table associated with a wide projection screen. The system tracks the cards unique identification and position allowing an easy an immediate apprehendability that triggers deep exploration. This interface should promote a rich flanêrie inside a content that keeps tracks, illustrates a precise subject and reveals new links between objects.

\section{Learning with Digital Technologies in Museums}

The museum's role in the formation of scientific literacy has been widely discussed [6]. A major issue concerns the establishment of the frontiers between the school and the museums environment. Indeed, the traditional visit guided by a teacher may result in student weariness, due to the mimic of similar methods in classrooms. In his research, Hawkey [2] argues that teachers shouldn't use museum objects just as illustrations for topics in courses and the galleries as an extension of the classroom. The new paradigms of this cooperation show that both institutions have their specific knowledge that should be respected and explored in complementary ways. The use of technology in schools and museums aims to bridge the gaps and explore the complementarities between the two specific methods and environments: the lecture and the object discovery. The visit to a museum invites the activities and experiences outside the classroom. The traditional educational tools enrich experiences for museums. In both cases this dialogue should stimulate the autonomy of students helping them building a personal experience based on a learning environment of free choice.

\subsection{The Museum Specific Case}

The Musée des arts et métiers in paris is a particular case in the world of scientific museum because of its historical relationship with the objects inherited from the old conservatory of techniques[7]. Objects and galleries are organized according to the object uses or specific characteristics. Inside the galleries visitors may walk freely, follow a determined path and also be supported by guide teachers of the museum with specific tours for groups with extensive demonstrations. In overall cases the visitors relationship with objects remains passive. Actually the museum offers video explanations of objects functions but they are poor in interaction and are only made for an individual use. Moreover objects that are shown in the museum represent around $10 \%$ of the overall collection. Many objects are indeed kept in a reserve. Information on these objects cannot be accessed from inside the museum and create a physical link with them is impossible. Users can consult the object list on the website of the museum but the catalog is limited to still pictures and very basic information. This section of the website is primarily intended for professionals who wish to submit applications for loans. For a personalized visit and to guarantee a close relation with objects a solution is needed to keep tracks of object choices made during the visit [8][9][10]. The Digital Backpacking project at the Austrian museum of techniques 
proposed an object selection strategy based on an RFID smartcard. Visitors where invited to buy the card that stores object information collected during the visit for immediate use on terminals and to keep it as a souvenir for post-visit debriefing [11]. We wish to extend this strategy and give the users a simple and cheap tangible link with objects that can also be used as input device for the multimedia kiosk and or in a web application from home.

\section{Suggested Scenario of Use}

We propose now to describe an use case scenario to clarify the use of our interactive $3 \mathrm{D}$ catalogue. The main characters are taken from a family composed by a couple and two children of 12 and 10 years old. The visit is made by the father and his two children. At the museums entrance they buy 3 admission tickets represented by small rectangular paper cards. This card has the museum logo and a unique barcode that identifies a single user. Initially conceived for controlling visitor entrances they will serve later as an individual identification in our system. The family starts the visit following a suggested path. During their visit, some objects catch the attention of the children. To obtain more information later, a child can pick one of the cards available next to the object. Over one side of each ticket there is an illustration of the object and on the other side a fiducial mark. This mark is part of the reactivision system and identifies the object and will permit later the manipulation of the virtual environment. At a certain point of the visit path, the visitors are confronted with the multimedia kiosk consisting in a tabletop device associated with big projection screen (fig.1). On the screen a galaxy of floating objects is displayed. On the table the children can touch these particles, which react to the touch by revealing their 3D representations. One of the children disposes the ticket over the table. The corresponding particle is placed near the card and reveals its 3D representation. The child tries other tickets and for each one, he gets an overview of the 3D objects. He notices that he can rotate and move on the screen this virtual object in order to have an overview of the object. Simultaneously other related objects are attracted revealing new semantic connections, possibly with objects that are kept in the reserve. He can have a closer look to these new attracted objects by clicking on them and once again the 3D representations are revealed. Other operations can be performed on selected object, such as launching $3 \mathrm{D}$ animations to understand object functions or rendering parts with transparency to show hidden mechanisms.

The experience lasts from 5 to 10 minutes. The child has played around with the particles and the $3 \mathrm{~d}$ representations and he is invited to put his entrance ticket on the table. The objects close to him are stored in a remote server with his personal ID printed on the ticket. The child has new insights in how to walk the museum and have a better overview of the different fields covered by the museum. Once the family is back home they can visualize the objects but also the new links that have been created with more less time constraint with the web dedicated interface. The interface simulates the museum kiosk experience and is built with more multimedia material 


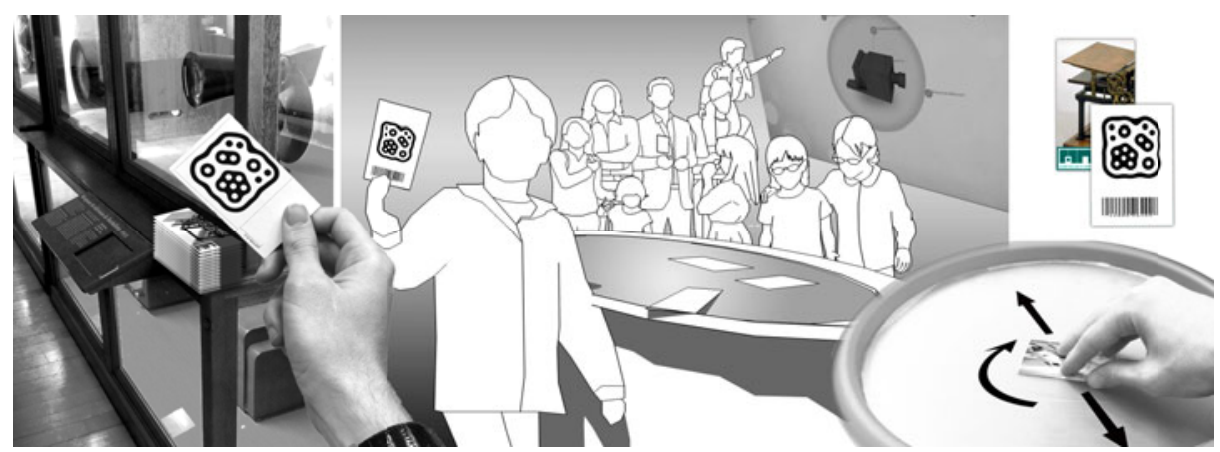

Fig. 1. Paper cards representing object selection. Museum kiosk installation and basic gestures for 3D manipulation.

and external resources associated with objects. They can explain the visit to parents and friends with a visual support. By this stimulating narration act they turn passive and forgettable knowledge into active and durable. For a collaborative aspect, in that web interface they can add comments and share web-links. For school use, teachers can ask expressly a certain number of objects to be collected and easily debrief the children personal experience with their cards and make a history of their visit. Children can also exchange cards and get information from others. This system permits a simple and not expensive way to stimulate the quest for information and the cards became easy to use manipulation devices made of paper that can link the real visit experience with a virtual visit. The paper solution permits cards to be taken home and act as both as a souvenir of the museum visit and as an entry point for the multimedia devices and the website.

\section{System Overview}
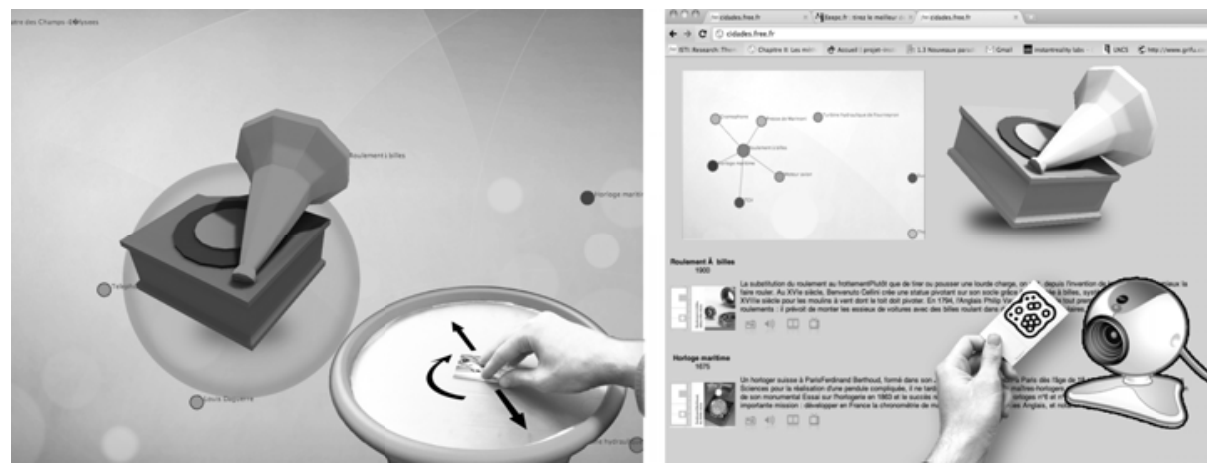

Fig. 2. Kiosk and website graphic interfaces with their related input styles: tabletop gestures at the museum kiosk and a webcam for home use 
In this section, we will mainly talk about technical and design aspects of the kiosk device installation (inside the museum). The reason why we don't talk specifically about the private (website accessible from anywhere) is because this last system is a subset of the first one. It only needs a standard computer running the same Java visualization application rendered on a single screen instead of two. For the computer vision inputs, a simple home webcam is enough to allow the same set of interaction of the museum kiosk. Instead of moving the card on a tabletop, the user, at home, will present it to his webcam. The multimedia kiosk is a multitouch tabletop device that tracks fingers and fiducial markers in real-time through the computervision framework reactvision [12]. The image captured by an infrared camera sends position and angle information of the mark by a TUIO protocol understanding client that renders the visualization. To implement our prototype we have used processing as our multimedia development environment (www.processing.org). The graphical interface presents the $3 \mathrm{D}$ objects as a galaxy of moving spheres that we call particles. Each particle has a color computed by mixing the scientific fields segmentation of the museum according to the semantical closeness of an object to each field. (fig.2) Thus each object belongs to his original domain but they may also be related to other areas (and this appears thought the color given to its particle). We developed an XML file that stores objects tagging information with reduced data like title, author, and date reproducing what is already been implemented for the traditional web catalog. We enriched this initial tagging with the nuanced domain classification. Then for each particle we implemented a calculation of Euclidean distance in $n$-dimensional space, where $n$ is the number of areas related to the individual object. This distance is used to determine the degree of similarity between objects and it sets the movement behavior of each particle. Objects are more or less attracted and with different speeds according to their similarities. The movement behavior was inspired by a metaphor of magnetic fields and the similarity distance computed reproduces physical laws of magnetism. The result is very fluid and smooth interactive experience without visual discontinuity or occluded levels of complexity.

\subsection{Interacting with Particles}

As a new object card is placed upon the table, the related object is highlighted giving an overview of the 3D digitized object. The fiducial mark printed on the card allows the user to move, turn and act on the 3D object. This is done by using 3 degrees of freedom offered by the card: the 2 standard translations in $\mathrm{X}$ and $\mathrm{Y}$ directions like a mouse and the rotation used to either turn the object or advance in an animation timeline. For each selected object similar objects starts to move towards it. The final pattern gives information on similarity from the surrounding objects. A series of concentric fields outlines the area of most similar and relevant objects. The user can touch attracted objects that will expand to reveal their 3D representation and turn around they're selves automatically as in a turntable metaphor. If new cards are added to the table a new net of relations will emerge taking into account the new cards and their attracted objects. Each user will have its own area on the table with possibly the same objects attracted. If a same card is used, duplicated particles will show up to 
avoid a lack of possible particles to be attracted. This way multiple users can enjoy at the same time the kiosk, sharing cards in a collaborative way and making new discoveries together.

\section{Conclusions and Future Work}

We have explored in this article a way to access a 3D database of digitized objects from the museum galleries and reserve. Our systems permit a simple and not expensive way to interact with 3D assets as they are made of paper on which are printed fiducial marks. Because these interaction devices are made of paper they can be taken home as a souvenir of the museums visit and as keys to enter the museums website. Several informal tests were conducted with the museum coordinators and with visitors. The use of cards was immediately apprehended and the manipulation of objects seamed obvious and natural. Besides the risk that every card available would be picked the possibility to bring home a key to a new web experience motivated the visitors.

\section{References}

1. Damala, A.: Edutainment Games for Mobile Multimedia Museum Guidance Systems: A Classification Approach. In: Natkin, S., Dupire, J. (eds.) ICEC 2009. LNCS, vol. 5709, pp. 307-308. Springer, Heidelberg (2009)

2. Hawkey, R.: Learning with digital technologies in museums, science centres and galleries. NESTA Futurelab (2004)

3. Cho, H.-S., Lee, B., Lee, S., Kim, Y., Cho, Y., Kang, S.-M., Park, S., Park, K., Hahn, M.: The Development of a Collaborative Virtual Heritage Edutainment System with Tangible Interfaces. In: Harper, R., Rauterberg, M., Combetto, M. (eds.) ICEC 2006. LNCS, vol. 4161, pp. 362-365. Springer, Heidelberg (2006)

4. Hornecker, E.: "I don't understand it either, but it is cool"-visitor interactions with a multitouch table in a museum. In: 3rd IEEE International Workshop on Horizontal Interactive Human Computer Systems, TABLETOP 2008, pp. 113-120 (2008)

5. Taxén, G., Bowers, J., Hellström, S., Tobiasson, H.: Designing Mixed Media Artefacts for Public Settings. In: Cooperative Systems Design: Scenario-Based Design of Collaborative Systems, vol. 195 (2004)

6. Girault, Y.: L'accueil des publics scolaires dans les museums: Aquariums, jardins Botaniques, parcs zoologiques. Editions L'Harmattan (2003)

7. Durant, J., Ferriot, D.: The role of the object in techni-cal museum: the Conservatoire National d'Arts et Métier. In: Museums and the Public Understanding of Science, NMSI Trading Ltd. (1992)

8. Fleck, M., Frid, M., Kindberg, T., O’Brien-Strain, E., Rajani, R., Spasojevic, M.: Rememberer: A tool for capturing museum visits. In: Borriello, G., Holmquist, L.E. (eds.) UbiComp 2002. LNCS, vol. 2498, pp. 379-385. Springer, Heidelberg (2002)

9. Astic, I., Aunis, C., Damala, A., Gressier-Soudan, E.: An ubiquitous mobile edutainment application for learning science through play. In: Museums and the Web, MW 2011, Philadelphia, USA (2011) 
10. Ullmer, B., Ishii, H.: MediaBlocks: tangible interfaces for online media. In: CHI 1999 Extended Abstracts on Human Factors in Computing Systems, pp. 31-32 (1999)

11. Hornecker, E., Stifter, M.: Digital backpacking in the museum with a SmartCard. In: Proceedings of the 7th ACM SIGCHI New Zealand Chapter's International Conference on Computer-Human Interaction: Design Centered HCI, pp. 99-107 (2006)

12. Jorda, S., Kaltenbrunner, M., Geiger, G., Bencina, R.: The reactable. In: Proceedings of the International Computer Music Conference (ICMC 2005), Barcelona, Spain, pp. 579-582 (2005) 